\title{
Run and Gait Analysis in Junior Badminton Players of South Asia
}

\author{
Manan Vora ${ }^{1,3 *}$, Digpal Ranawat ${ }^{1,2}$, Manit Arora ${ }^{1,3}$ and Apoorva Tiwari $^{2}$ \\ ${ }^{1}$ Abhinav Bindra Targeting Performance, Mohali, India
}

${ }^{2}$ Abhinav Bindra Targeting Performance, Bangalore, India

${ }^{3}$ Fortis Hospital, Mohali, India

Submission: June 24, 2019; Published: July 17, 2019

*Corresponding author: Manan Vora, Abhinav Bindra Targeting Performance, Mohali, India

\begin{abstract}
An ideal walking and running pattern are very important for an athlete. Badminton is a physically demanding sport and it is not uncommon for players to have muscle tightness and imbalances that may cause restricted joint range of motion and body load asymmetry. Detection and prevention of these abnormal patterns may help prevent injuries and result in overall improvement in performance. Accordingly, the study was proposed to analyse the gait and run pattern in junior badminton players and understand the importance of prevention of muscle tightness and imbalance. A total of 100 players from South Asia between the age of 8 and 15 years were analysed. Walker View system of Tecnobody Italy was used. Variables measured were gender, height, age, body mass index, and experience in years, level at which they play, current pain, and clicks \& catches in the past 1 year. Our study showed that there were quite a few factors that affected an athlete's gait and run pattern. There needs to be a greater focus on early detection of these abnormalities and on prevention of muscle tightness and imbalances with the help of specific training, strength \& conditioning, and rehabilitation as part of the development of junior badminton players.
\end{abstract}

Keywords: Gait analysis; Run analysis; Performance; Racquet sport; Muscle imbalance; Biomechanics

\section{Introduction}

The intermittent nature of badminton makes it hard to determine exactly what is happening physiologically, because so much is dependent on standard of players, the type of game being played, the duration of the play, coordination, mental acuity and the environmental conditions encountered Mikkelsen [1]. Great athletes make difficult moves look effortless with a combination of skill, strength, and balance and accordingly, train for smooth and fluid movement to help prevent muscle imbalances, mobility restrictions, stability problems, and injuries Cook [2]. It has been previously established that the biomechanical rationale for achieving and maintaining optimal posture is to move efficiently, free of impairment and dysfunction Kritz \& Cronin [3]. Human motion analysis is receiving increasing attention from researchers, including athletic performance analysts Aggarwal \& Cai [4]. Gait analysis has now advanced to the point where it is used as a routine part of patient management in certain centres Whittle [5]. It is best thought of as a special investigation, which is used together with the history, physical examination and other special investigations to perform a detailed assessment of a patient with a walking disorder Whittle [5]. The first results of a complete marker free methodology for human gait analysis was recorded and after having reconstructed the 3D model of the human, gait parameters were extracted and analysed in order to detect pathologies or abnormalities Desseree-Calais \& Legrand [6]. Gait analysis measures the effects of combined causes and compensatory activities of the body Rose [7]. It has been studied previously but is generally done to check gait abnormalities post injury/pain. It was studied in patients with anterior knee pain Callaghan \& Baltzopoulos [8]. Plantar pressure distribution during gait in athletes with functional instability of the ankle joint has also been studied Nawata, Nishihara, Hayashi, \& Teshima [9]. Gait patterns between ACL reconstructed athletes who pass return-to-sport criteria and those who fail were studied and found to be different Di Stasi, Logerstedt, Gardinier, \& Snyder-Mackler [10].

For an athlete, an ideal gait or running pattern is very important. Bilaterally symmetrical joint range of motion is key to ensuring an athlete is moving correctly in his/her sport. One of the reasons for a difference in joint range of motion between the right and left sides of the body is muscle tightness and imbalances around that particular joint restricting and limiting its movement Ranawat [11]. Muscle imbalance occurs when muscles become constantly shortened or lengthened in relation to each other Norris [12]. Few studies have been done on muscle imbalance in sport. The relationship between hip muscle imbalance and occurrence of low back pain in athletes 
has been studied Nadler [13]. Shoulder muscle imbalance and subacromial impingement syndrome in overhead athletes has been documented Page [14]. Muscle imbalances of the lower extremities in competitive sports like basketball and volleyball have been analysed Sommer [15]. A preliminary alternative approach in an attempt to assess muscle function in relation to both- performance \& injury prevention and muscular recovery after injury has been documented as well Schlumberger [16]. Additionally, strength imbalances in professional soccer players has been discussed as well Croisier, Ganteaume, Binet, Genty, \& Ferret [17]. Studies on the co-elation between posture and its importance in sport have also been conducted Hébert-Losier \& Rahman [18], Watson \& Mac Donncha [19], Padua \& Hirth [20], Oddsson \& De Luca [21].

A study on the epidemiology of injuries in elite badminton athletes showed that the most common region of pain in the body is the back Yung, Chan, Wong, Cheuk, \& Fong [22], Goh, Mokhtar, \& R. Mohamad Ali [23]. Studies have shown that most sports injuries are related to flexibility, posture, acceleration, clinical defects, and previous injury Watson [24]. A study was also conducted on the sports injuries in footballers related to defects of posture and body mechanics with the objective being to investigate possible relationships between the incidence of sports injury and the existence of body mechanics defect in players Watson [25]. Studies co-relating injuries to muscular imbalances have been documented such as a relationship between shoulder mobility, rotator muscles' strength and scapular symmetry, and shoulder injuries and/or pain in elite volleyball athletes Wang \& Cochrane [26]. A prospective study of overuse knee injuries among female athletes with muscle imbalances and structural abnormalities has been conducted Devan, Pescatello, Faghri, \& Anderson [27]. The purpose of this study was to identify the modifiable and non-modifiable factors that contribute to abnormalities in the walking and running pattern in badminton players, resulting in an increased risk of injury. Non-modifiable factors include gender, height, age and years of experience. Modifiable factors include body mass index, level, current pains, clicks and catches in the body.

\section{Methodology}

One hundred junior badminton players under the aegis of Badminton Association of India (BAI) were recruited for the study. Informed consent from the players, legal guardians and coaches was taken prior to participation. Approval from the BAI was taken prior to initiation of the study. All players were screened using a combination of a questionnaire and machine analysis. The questionnaire consisted of a self-developed item set with focus on demographics, injury history, treatment history, playing career history and current injury state. The demographic data included age, sex, height, weight, and dominant hand. The injury history included questions regarding injuries in the past, their severity, whether they occurred during competition, training or daily activity, whether it prevented the player from taking part in a competition and/or training and/ or daily activity, and if the pain was more during a particular badminton stroke. The treatment history questioned the form of treatment taken for the injuries, whether it was oral medication, physiotherapy, surgery, or any other. Playing career history included information regarding the age at which the player began playing badminton, whether the player has a dedicated coach and/or trainer, age at which he/she began playing badminton tournaments, and current professional level. Current injury state involved questions regarding any current pain faced by the player, and whether the player has experienced any clicks, cracks or catches in the body in the last 12 months.
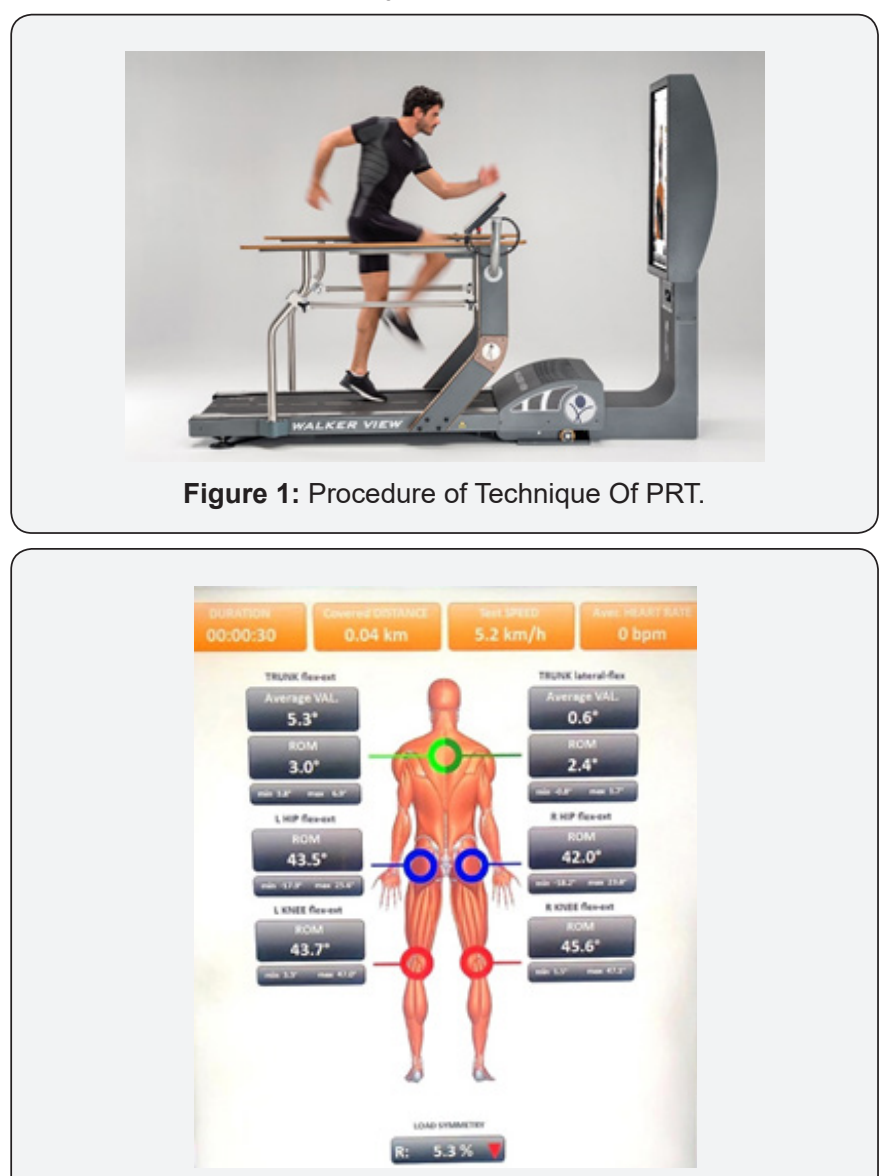

Figure 2: Final report of Walker View System of Tecnobody Italy.

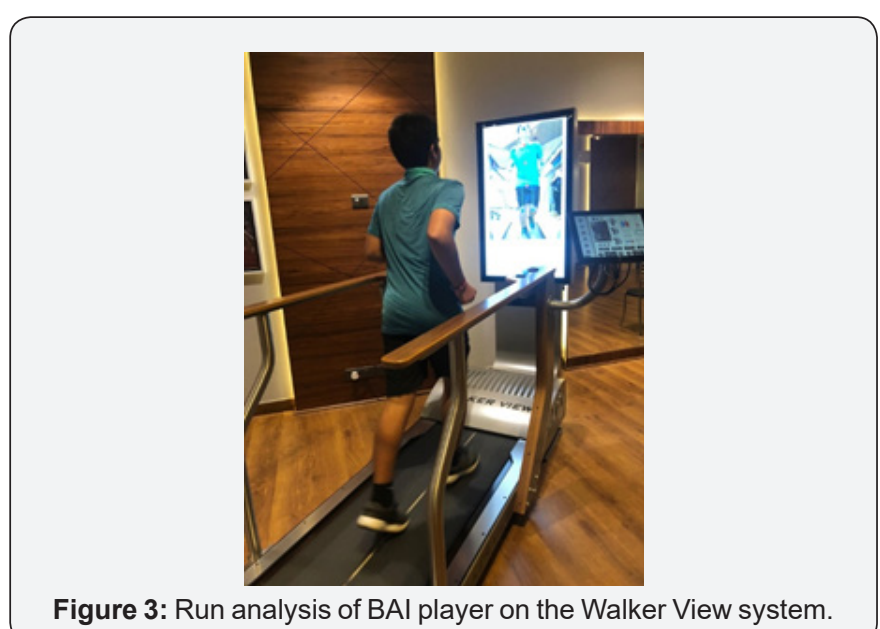

Figure 3: Run analysis of BAI player on the Walker View system. 


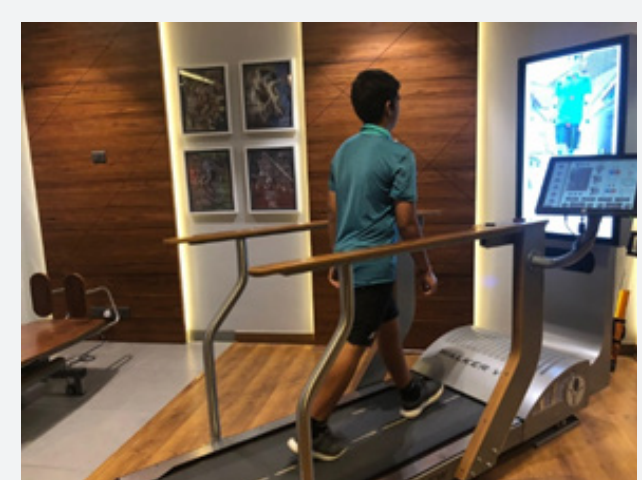

Figure 4: Gait analysis of BAI player on the Walker View system.

The machine analysis was done by conducting a run and gait analysis. Walker View system of Tecnobody Italy (Figure 1) was used. The Tecno Body treadmill is equipped with a sensitive load cell belt. This technology allows the assessment of stance during ambulation and corrects dynamic parameters in real time. The Table 1: Difference in Trunk range of motion.

\begin{tabular}{|c|c|c|c|c|c|c|}
\hline Variables & Groups & $\mathbf{N}$ & Run Mean \pm SD & Run 'P' & Gait Mean \pm SD & Gait ' $P$ ' \\
\hline \multirow{2}{*}{ Gender } & Male & 59 & $0.59 \pm 0.56$ & \multirow{2}{*}{0.76} & $0.65 \pm 0.83$ & \multirow{2}{*}{0.47} \\
\hline & Female & 41 & $0.64 \pm 0.45$ & & $0.64 \pm 0.45$ & \\
\hline \multirow{2}{*}{ Height (In Cms) } & Below 150 & 21 & $0.54 \pm 0.46$ & \multirow{2}{*}{0.41} & $0.54 \pm 0.46$ & \multirow{2}{*}{0.42} \\
\hline & Above 150 & 79 & $0.63 \pm 0.53$ & & $0.64 \pm 0.45$ & \\
\hline \multirow{2}{*}{ Age (In Years) } & $<12$ & 39 & $0.52 \pm 0.41$ & \multirow{2}{*}{$0.01^{*}$} & $0.77 \pm 0.45$ & \multirow{2}{*}{0.54} \\
\hline & $>12$ & 61 & $0.75 \pm 0.62$ & & $0.61 \pm 0.75$ & \\
\hline \multirow{2}{*}{ BMI (In kg/M2) } & $<18$ & 42 & $0.68 \pm 0.51$ & \multirow{2}{*}{0.87} & $0.69 \pm 0.51$ & \multirow{2}{*}{0.7} \\
\hline & $>18$ & 58 & $0.57 \pm 0.52$ & & $0.62 \pm 0.81$ & \\
\hline \multirow{2}{*}{ Experience (In Years) } & $<5$ & 44 & $0.68 \pm 0.54$ & \multirow{2}{*}{0.21} & $0.68 \pm 0.53$ & \multirow{2}{*}{0.9} \\
\hline & $>5$ & 56 & $0.56 \pm 0.50$ & & $0.62 \pm 0.81$ & \\
\hline \multirow{2}{*}{ Level } & Amateur & 34 & $0.52 \pm 0.39$ & \multirow{2}{*}{0.07} & $0.53 \pm 0.39$ & \multirow{2}{*}{0.13} \\
\hline & Professional & 66 & $0.66 \pm 0.56$ & & $0.70 \pm 0.80$ & \\
\hline \multirow{2}{*}{ Current pain } & Yes & 24 & $0.64 \pm 0.37$ & \multirow{2}{*}{0.08} & $0.64 \pm 0.37$ & \multirow{2}{*}{0.14} \\
\hline & No & 76 & $0.60 \pm 0.55$ & & $0.65 \pm 0.77$ & \\
\hline licks \& Catches in Past 1 yr & Yes & 23 & $0.45 \pm 0.38$ & 0.11 & $0.65 \pm 0.38$ & 0.17 \\
\hline
\end{tabular}

Run: As seen in Table 1, there is a significant difference in Trunk range of motion between those aged below and above 12 .

Gait: As seen in Table 1, there is no significant difference in Trunk range of motion.

*Significant difference level at (0.05).

Table 2: Difference in Hip range of motion.

\begin{tabular}{|c|c|c|c|c|c|c|}
\hline & & & SD & & & \\
\hline \multirow{2}{*}{ Gender } & Male & 59 & $2.37 \pm 2.87$ & \multirow{2}{*}{0.52} & $3.27 \pm 4.40$ & \multirow{2}{*}{0.17} \\
\hline & Female & 41 & $2.28 \pm 1.81$ & & $2.62 \pm 2.10$ & \\
\hline \multirow{2}{*}{ Height (In Cms) } & Below 150 & 21 & $2.10 \pm 1.29$ & \multirow{2}{*}{0.27} & $2.10 \pm 1.29$ & \multirow{2}{*}{0.17} \\
\hline & Above150 & 79 & $2.34 \pm 2.81$ & & $3.22 \pm 3.67$ & \\
\hline \multirow{2}{*}{ Age (In Years) } & $<12$ & 39 & $2.15 \pm 1.59$ & \multirow{2}{*}{0.16} & $2.18 \pm 1.38$ & \multirow{2}{*}{0.15} \\
\hline & $>12$ & 61 & $2.42 \pm 2.96$ & & $3.25 \pm 2.73$ & \\
\hline \multirow{2}{*}{ BMI (In kg/M2) } & $<18$ & 42 & $2.15 \pm 1.43$ & \multirow{2}{*}{0.09} & $3.16 \pm 5.29$ & \multirow{2}{*}{0.65} \\
\hline & $>18$ & 58 & $2.62 \pm 3.04$ & & $2.90 \pm 4.97$ & \\
\hline \multirow{2}{*}{ Experience (In Years) } & $<5$ & 44 & $2.29 \pm 1.74$ & \multirow{2}{*}{0.23} & $2.50 \pm 2.09$ & \multirow{2}{*}{0.07} \\
\hline & $>5$ & 56 & $2.34 \pm 2.95$ & & $3.40 \pm 2.45$ & \\
\hline
\end{tabular}




\section{Journal of Physical Fitness, Medicine \& Treatment in Sports}

\begin{tabular}{|c|c|c|c|c|c|c|}
\hline \multirow{2}{*}{ Level } & Amateur & 34 & $2.25 \pm 2.05$ & \multirow{2}{*}{0.87} & $3.72 \pm 5.5 .47$ & \multirow{2}{*}{0.18} \\
\hline & Professional & 66 & $2.44 \pm 2.71$ & & $2.64 \pm 4.21$ & \\
\hline \multirow{2}{*}{ Current Pain } & Yes & 24 & $2.00 \pm 2.53$ & \multirow{2}{*}{$0.03^{*}$} & $3.01 \pm 4.65$ & \multirow{2}{*}{0.30} \\
\hline & No & 76 & $3.32 \pm 3.47$ & & $2.69 \pm 4.46$ & \\
\hline \multirow{2}{*}{$\begin{array}{c}\text { Clicks \& Catches in } \\
\text { Past } 1 \mathrm{yr}\end{array}$} & Yes & 23 & $2.09 \pm 1.95$ & \multirow{2}{*}{$0.02^{*}$} & $3.0 \pm 5.80$ & \multirow{2}{*}{0.24} \\
\hline & No & 77 & $3.26 \pm 3.47$ & & $2.69 \pm 4.46$ & \\
\hline
\end{tabular}

Run: As seen in Table 2, there is significant difference in Hip range of motion between those who have current pain and don't and those who experienced clicks and catches in the past 1 year and those who didn't.

Gait: As seen in Table 2, there is no significant difference in Hip range of motion.

*Significant difference level at (0.05).

Table 3: Difference in Knee range of motion

\begin{tabular}{|c|c|c|c|c|c|c|}
\hline Variables & Groups & $\mathbf{N}$ & Run Mean \pm SD & Run 'P' & Gait Mean \pm SD & Gait ' $P$ ' \\
\hline \multirow{2}{*}{ Gender } & Male & 59 & $2.91 \pm 3.09$ & \multirow{2}{*}{0.16} & $3.13 \pm 3.14$ & \multirow{2}{*}{0.19} \\
\hline & Female & 41 & $2.79 \pm 2.09$ & & $3.08 \pm 2.63$ & \\
\hline \multirow{2}{*}{ Height (In Cms) } & Below 150 & 21 & $2.40 \pm 1.81$ & \multirow{2}{*}{0.32} & $2.81 \pm 2.56$ & \multirow{2}{*}{0.70} \\
\hline & Above150 & 79 & $2.98 \pm 2.91$ & & $3.20 \pm 3.04$ & \\
\hline \multirow{2}{*}{ Age (In Years) } & $<12$ & 39 & $2.73 \pm 2.91$ & \multirow{2}{*}{0.71} & $2.94 \pm 2.31$ & \multirow{2}{*}{0.23} \\
\hline & $>12$ & 61 & $2.81 \pm 2.98$ & & $3.16 \pm 3.90$ & \\
\hline \multirow{2}{*}{ Bmi (In kg/M2) } & $<18$ & 42 & $2.91 \pm 3.42$ & \multirow{2}{*}{0.28} & $3.06 \pm 3.50$ & \multirow{2}{*}{0.32} \\
\hline & $>18$ & 58 & $2.85 \pm 2.13$ & & $3.15 \pm 2.46$ & \\
\hline \multirow{2}{*}{ Experience (In Years) } & $<5$ & 44 & $2.78 \pm 2.50$ & \multirow{2}{*}{0.93} & $3.35 \pm 2.98$ & \multirow{2}{*}{0.37} \\
\hline & $>5$ & 56 & $2.86 \pm 2.98$ & & $2.92 \pm 2.89$ & \\
\hline \multirow{2}{*}{ Level } & Amateur & 34 & $2.87 \pm 2.43$ & \multirow{2}{*}{0.94} & $3.25 \pm 3.05$ & \multirow{2}{*}{0.57} \\
\hline & Professional & 66 & $2.89 \pm 2.87$ & & $3.04 \pm 2.88$ & \\
\hline \multirow{2}{*}{ Current Pain } & Yes & 24 & $2.56 \pm 2.91$ & \multirow{2}{*}{$0.04^{*}$} & $2.75 \pm 2.29$ & \multirow{2}{*}{$0.001^{*}$} \\
\hline & No & 76 & $3.80 \pm 4.01$ & & $4.25 \pm 4.14$ & \\
\hline \multirow{2}{*}{ Clicks \& Catches in Past 1 yr } & Yes & 23 & $2.54 \pm 2.71$ & \multirow{2}{*}{$0.03^{*}$} & $2.72 \pm 2.29$ & \multirow{2}{*}{$0.001 *$} \\
\hline & No & 77 & $3.95 \pm 4.03$ & & $4.43 \pm 4.24$ & \\
\hline
\end{tabular}

Run: As seen in Table 3, there is a significant difference in Knee range of motion between those who have current pain and don't and those who experienced clicks and catches in the past 1 year and those who didn't.

Gait: As seen in Table 3, there is a significant difference in Knee range of motion between those who have current pain and don't and those who experienced clicks and catches in the past 1 year and those who didn't

*Significant difference level at (0.05).

Table 4: Difference in Knee range of motion

\begin{tabular}{|c|c|c|c|c|c|c|}
\hline Variables & Groups & $\mathbf{N}$ & Run Mean \pm SD & Run 'P' & Gait Mean \pm SD & Gait 'P' \\
\hline \multirow{2}{*}{ Gender } & Male & 59 & $2.80 \pm 2.25$ & \multirow{2}{*}{0.77} & $2.56 \pm 2.21$ & \multirow{2}{*}{0.36} \\
\hline & Female & 41 & $1.99 \pm 2.51$ & & $2.63 \pm 2.58$ & \\
\hline \multirow{2}{*}{ Height (In Cms) } & Below 150 & 21 & $2.21 \pm 1.26$ & \multirow{2}{*}{0.06} & $2.85 \pm 2.64$ & \multirow{2}{*}{0.97} \\
\hline & Above150 & 79 & $2.54 \pm 2.78$ & & $2.53 \pm 2.33$ & \\
\hline \multirow{2}{*}{ Age (In Years) } & $<12$ & 39 & $1.69 \pm 1.39$ & \multirow{2}{*}{0.08} & $2.73 \pm 2.61$ & \multirow{2}{*}{0.31} \\
\hline & $>12$ & 61 & $2.97 \pm 2.96$ & & $2.55 \pm 2.29$ & \\
\hline \multirow{2}{*}{ Bmi (In kg/M2) } & $<18$ & 42 & $2.86 \pm 3.26$ & \multirow{2}{*}{$0.03^{*}$} & $2.65 \pm 2.54$ & \multirow{2}{*}{0.12} \\
\hline & $>18$ & 58 & $2.21 \pm 1.88$ & & $2.54 \pm 2.23$ & \\
\hline \multirow{2}{*}{ Experience (In Years) } & $<5$ & 44 & $2.12 \pm 2.27$ & \multirow{2}{*}{0.61} & $2.59 \pm 2.57$ & \multirow{2}{*}{0.18} \\
\hline & $>5$ & 56 & $2.75 \pm 2.72$ & & $2.58 \pm 2.20$ & \\
\hline \multirow{2}{*}{ Level } & Amateur & 34 & $2.22 \pm 2.28$ & \multirow{2}{*}{0.36} & $2.46 \pm 2.35$ & \multirow{2}{*}{0.82} \\
\hline & Professional & 66 & $2.59 \pm 2.67$ & & $2.66 \pm 2.37$ & \\
\hline \multirow{2}{*}{ Current Pain } & Yes & 24 & $2.21 \pm 2.14$ & \multirow{2}{*}{$0.01^{*}$} & $3.39 \pm 2.90$ & \multirow{2}{*}{$0.01^{*}$} \\
\hline & No & 76 & $3.30 \pm 3.44$ & & $2.34 \pm 2.11$ & \\
\hline
\end{tabular}




\begin{tabular}{|c|c|c|c|c|c|c|}
\hline \multirow{2}{*}{ Clicks \& Catches in Past 1 yr } & Yes & 23 & $2.98 \pm 3.15$ & \multirow{2}{*}{0.19} & $3.50 \pm 2.91$ & \multirow{2}{*}{$0.01^{*}$} \\
\hline & No & 77 & $2.31 \pm 2.33$ & & $2.32 \pm 2.11$ & \\
\hline
\end{tabular}

Run: As seen in Table 4, there is a significant difference in load symmetry in those with a BMI less than and more than 18 and between those who have current pain and don't.

Gait: As seen in Table 4, there is significant difference in Load Symmetry between those who have current pain and don't and those who experienced clicks and catches in the past 1 year and those who didn't

*Significant difference level at (0.05).

Results
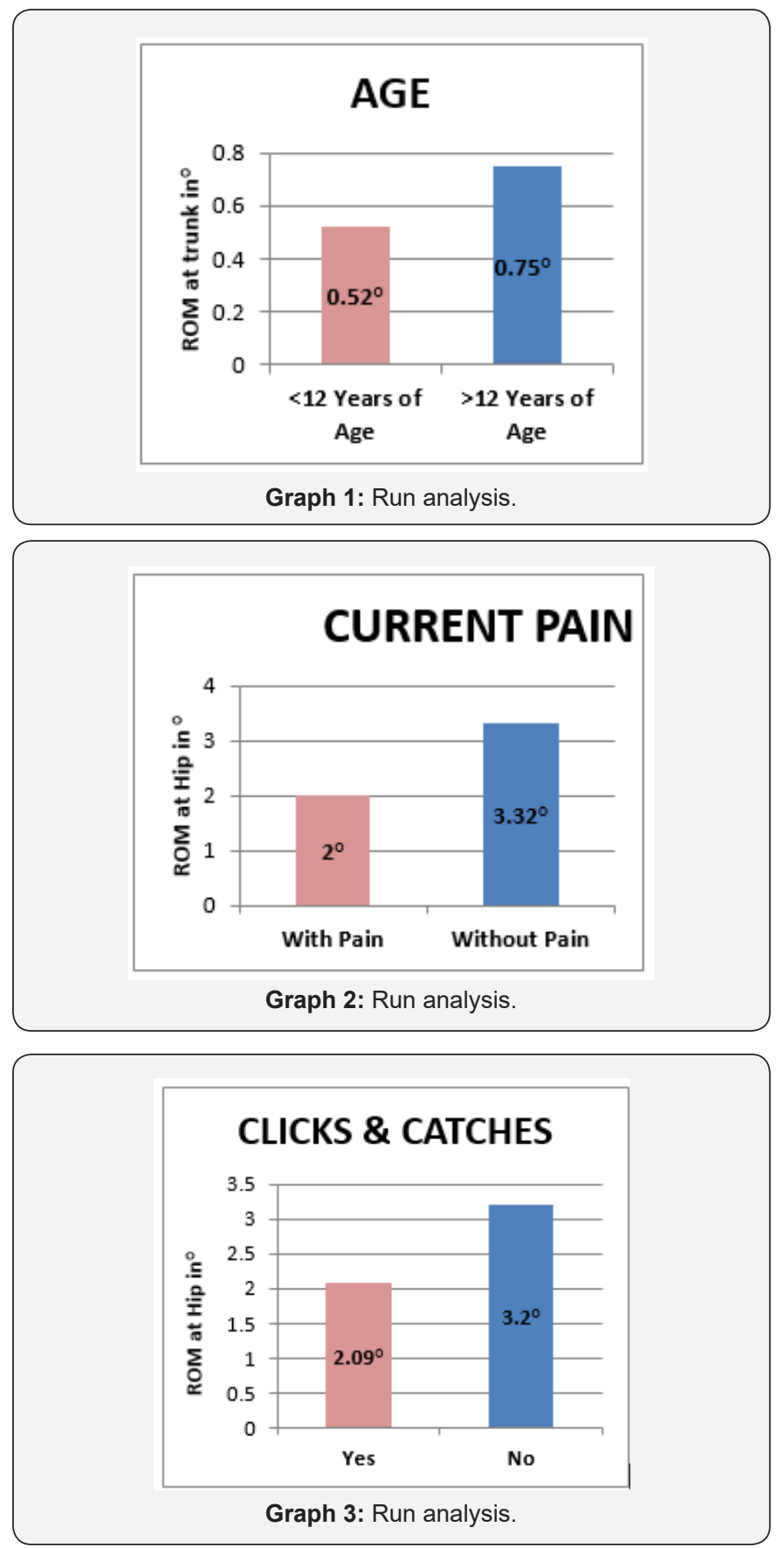

A total of 100 junior South Asian Badminton players underwent the assessment. Out of the 100 players, 59 were male players and 41 were female players. 90 of them were from India, 4 each from Nepal and Sri Lanka, while 2 players were from
Maldives. The age group was between 8 and 15 years. Gender, height, age, BMI, experience in years, level at which they play, current pain, and clicks \& catches in the past 1 year were the variables. The data is presented in Table 1-4. Table 1 shows difference in trunk range of motion between right and left sides of a body among various groups. Run- There is a significant difference (0.01) between those aged below and above 12 (Graph 1). Gait- There was no significant difference in across all variables. Table 2 highlights the difference in hip range of motion between right and left sides of the body. Run- We observed a significant difference between those who have current pain and don't (0.03) (Graph 2) and those who experienced clicks and catches in the past 1 year and those who didn't (0.02) (Graph 3). Gait- There was no significant difference in across all variables. Table 3 highlights the difference in knee range of motion between right and left sides of the body. Run- We observed a significant difference between those who have current pain and don't (0.04) (Graph 4) and those who experienced clicks and catches in the past 1 year and those who didn't (0.03) (Graph 5). Gait- There is a significant difference between those who have current pain and don't (0.001) (Graph 6) and those who experienced clicks and catches in the past 1 year and those who didn't (0.001) (Graph 7). Table 4 shows the difference in load symmetry between the right and left sides of the body. RunThere is a significant difference in those with a BMI less than and more than 18 (0.03) (Graph 8) and between those who have current pain and don't (0.01) (Graph 9). Gait- There is a significant difference in between those who have current pain and don't (0.01) (Graph 10) and those who experienced clicks and catches in the past 1 year and those who didn't (0.01).

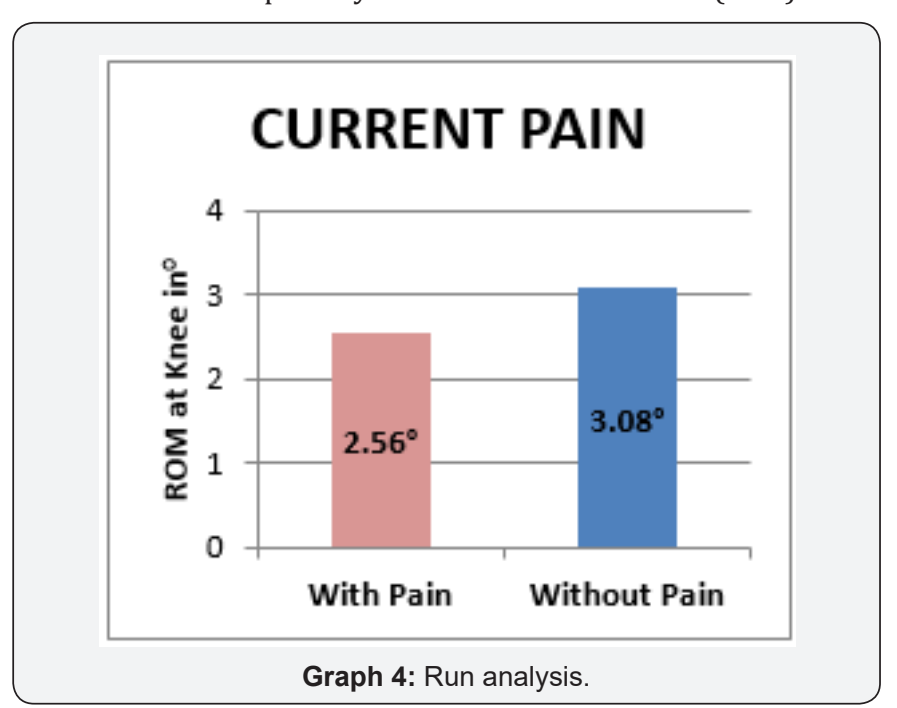



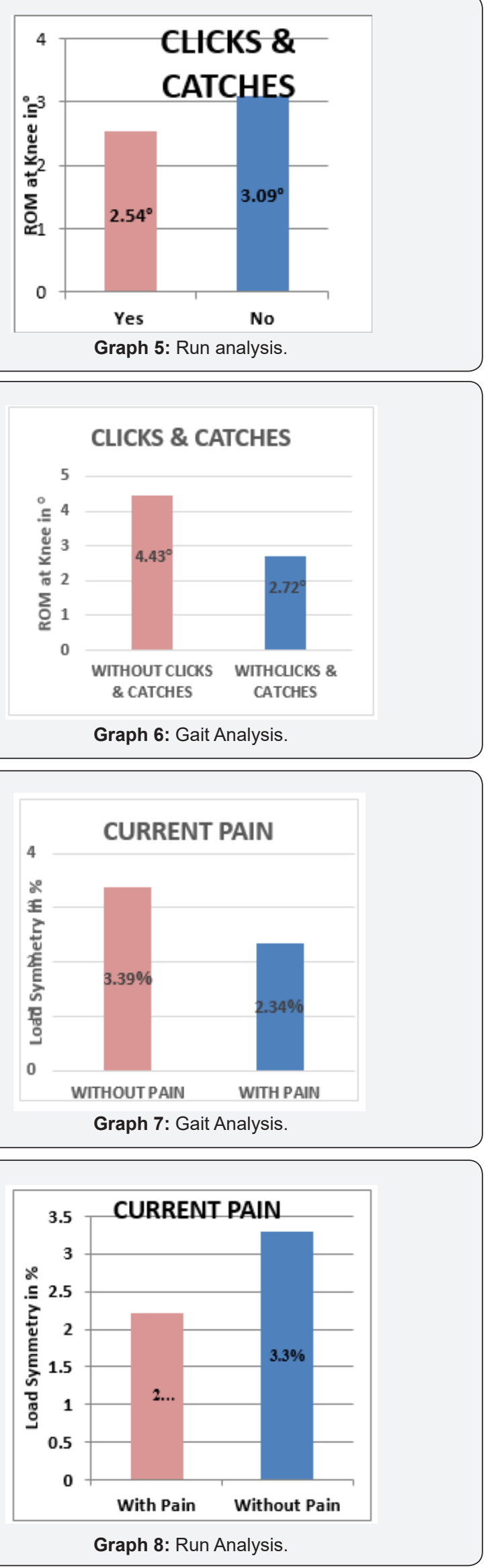
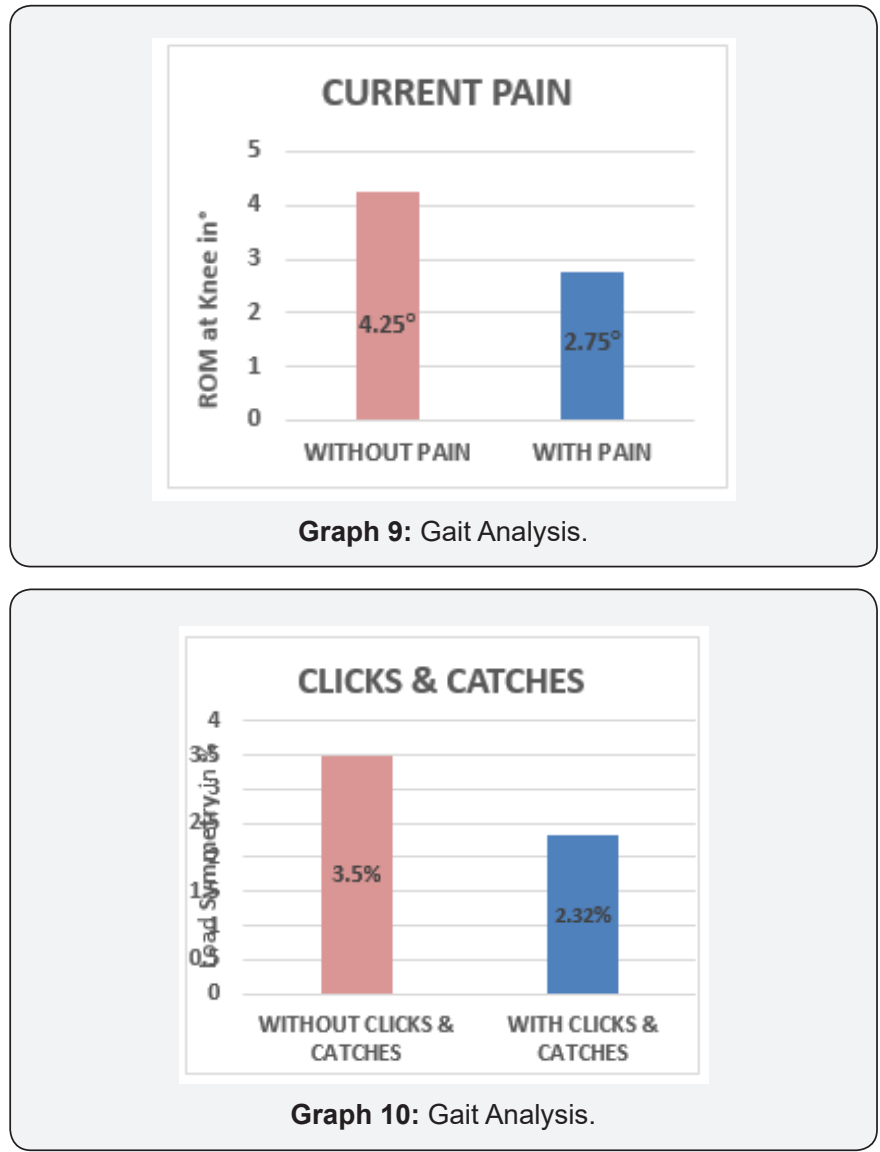

\section{Discussion}

Badminton requires specific physical conditioning in terms of action controls such as reaction time, foot stepping, and static or dynamic balances, which are essential motor demands in the sport Laffaye, Phomsoupha, \& Dor [28]. In addition to moving back and forth on the court, players conduct various movement patterns during the game including twists, jumps, and swings to strike the shuttle-cock Phomsoupha \& Laffaye [29]. Having an ideal gat and run pattern can be of utmost importance in a player's performance. But due to the high physical demands of the game, it is not surprising that badminton players may have abnormalities in their walking or running patterns. The results of our study have highlighted certain factors resulting in walking and running pattern abnormalities, but it also sheds light upon the lack of importance given by players and coaches in including a training and conditioning program in an athlete's regimen that focuses on improving their muscle tightness or imbalance, which could be the main reason for bilaterally asymmetrical joint range of motion and overall body load. We divided the variables into non-modifiable factors including gender, height, age and years of experience and modifiable factors including body mass index, level, current pains, clicks and catches in the body.

\section{Non-Modifiable Factors}

The factors in question here were gender, height, age and years of experience. There was a significant difference in the trunk range of motion between the right and left side in players 
below and above the age of 12 while running. The players above the age of 12 scored better and had lesser trunk range of motion asymmetry. This shows that younger players had greater trunk range of motion asymmetry which could be either due to muscle tightness or imbalances which later got corrected (either itself or by training) or as players get older, they develop better neuromuscular control over their trunk flexion and extension while run. Scapular and lumbar load asymmetry has been discussed by the current authors and it could play a role in decreased trunk range of motion Ranawat [11]. There was no significant difference found in hip range of motion while walking or running, however when the same authors tested hip stability and hip musculature in the sitting position, certain differences were found Manan, Digpal, Apoorva, \& Manit [30]. There was no significant difference observed between any of the other groups in both, run and gait analysis.

\section{Modifiable Factors}

The factors being considered here were body mass index, level of play, current pains, and presence of any clicks and catches in the body in the past 1 year. In run analysis, there was a significant difference in the hip and knee range of motion between those who have current pain and don't and those who experienced clicks and catches in the past 1 year and those who didn't. There was also a significant difference in load symmetry while running between those who have current pain and don't. In gait analysis, there was a significant difference in knee range of motion and load symmetry between those who have current pain and don't and those who experienced clicks and catches in the past 1 year and those who didn't. In all the above groups, athletes not having any current pain or not having experienced any clicks and catches in the past 1 year scored better than the injured or in-pain athletes. This shows that so many athletes go about their game while still injured or suffering from muscle tightness or imbalances causing restricted joint range of motion and asymmetrical body load distribution which could further increase their risk of injury.

A study conducted on football players showed that knee injuries were found to be associated with lumbar lordosis and sway back Watson [25]. It also stated that back injuries were associated with poor shoulder symmetry, scapulae abduction, back asymmetry, kyphosis, lordosis and scoliosis. In general, it was found that the incidence of ankle, back, knee and muscle injuries was influenced by the presence of defects of body mechanics and the results suggest that intervention to improve body mechanics would be likely to reduce the incidence of sports injuries in football Watson [25]. The importance of good posture in sport and prevention of muscle imbalance needs to be highlighted to players and their coaches to help prevent injuries and maximise performance. There was no significant difference observed between any of the other groups in both, run and gait analysis.

There are various studies that have suggested methods to assess muscle function and help prevent muscle imbalance
Kritz \& Cronin [3]. The authors suggested that the additional information provided by a posture assessment may assist the strength and conditioning professional in developing a strength programme that is more specific to the athlete's needs in order to enhance performance and possibly reduce the incidence of injury. To optimize function, an athlete should be suggested an integrated functional exercise program for stretching of potentially overactive and tight muscles, and for strengthening of underactive and weak musculature Padua \& Hirth [20]. The advantages of balance and stability training too have been highlighted. The authors indicate balance and stability training to be effective for gain in muscular strength and equalization of muscular imbalances Heitkamp, Horstmann, Mayer, Weller, \& Dickhuth [31], Manan [30]. Another study showed the concept of hip muscle imbalance being associated with low back pain occurrence in female athletes Nadler [13]. Their research further supported the need for the assessment and treatment of hip muscle imbalance in individuals with low back pain.

In a previous study, we assessed hip stability, helping us pin-point the exact region of muscle imbalance and treat it accordingly Manan [30]. Importance should also be given to injury prevention. Stretching before playing and cool down exercises after playing are necessary. It is also suggested that injury prevention programmes should concentrate on improving posture and the rehabilitation from previous injury, rather than flexibility Watson [24]. There were some limitations we faced in our study. Firstly, the participants included players between the ages of 8 and 15 years only. Secondly, the study could have included a wider geographical area including players from more Asian countries. Thirdly, an assessment after correction of muscle tightness and imbalance could have been done. This study opens up new grounds for further research. Further studies can address other variables not included in the present study. Additionally, targeted interventions are needed to correct the abnormalities and prevent muscle tightness and imbalance in athletes and the effect of such improvements on performance needs to be determined.

\section{Conclusion}

This study shows that there are various factors that affect an athlete's gait and run pattern. The key lies in early detection and correction of these abnormalities at a young age. In competitive sport, it's the small details that can end up making a large difference and identifying them is the first step. Consequently, understanding the need of injury prevention programmers, strength \& conditioning, and sports rehabilitation and its importance in overall improvement in badminton performance is vital and may help take a badminton player's fitness and game performance to a whole new level.

\section{References}

1. Mikkelsen F (1979) Physical Demands and Muscle Adaptation in Elite Badminton Players p. 1.

2. Cook G (2003) Athletic Body in Balance. 
3. Kritz MF, Cronin J (2008) Static Posture Assessment Screen of Athletes: Benefits and Considerations. Strength \& Conditioning Journal 30(5): 18.

4. Aggarwal JK, Cai Q (1999) Human Motion Analysis: A Review. Computer Vision and Image Understanding 73(3): 428-440.

5. Whittle MW (1996) Clinical gait analysis: A review. Human Movement Science 15(3): 369-387.

6. Desseree Calais EF, Legrand LR (2005) First Results of a Complete Marker-Free Methodology for Human Gait Analysis. In 2005 IEEE Engineering in Medicine and Biology $27^{\text {th }}$ Annual Conference pp. 7455 7458 .

7. Rose GK (1983) Clinical gait assessment: A personal view. J Med Eng Technol 7(6): 273-279.

8. Callaghan MJ, Baltzopoulos V (1994) Gait analysis in patients with anterior knee pain. Clinical Biomechanics 9(2): 79-84.

9. Nawata K, Nishihara S, Hayashi I, Teshima R (2005) Plantar pressure distribution during gait in athletes with functional instability of the ankle joint: preliminary report. Journal of Orthopaedic Science 10(3): 298-301.

10. Di Stasi SL, Logerstedt D, Gardinier ES, Snyder Mackler L (2013) Gait Patterns Differ Between ACL-Reconstructed Athletes Who Pass Return-to-Sport Criteria and Those Who Fail. The American Journal of Sports Medicine 41(6): 1310-1318.

11. Ranawat D, Vora M, Arora M, Tiwari A (2018) Analysis of Posterior Chain Muscle Symmetry in Junior Badminton Players of South Asia, J Phy Fit Treatment \& Sports 6(1).

12. Norris CM (1995) Spinal Stabilisation: 4. Muscle Imbalance and the Low Back. Physiotherapy 81(3): 127-138.

13. Nadler SF, Malanga GA, Feinberg JH, Prybicien M, Stitik TP, et al. (2001) Relationship Between Hip Muscle Imbalance and Occurrence of Low Back Pain in Collegiate Athletes: A Prospective Study. Am J Phys Med Rehabil 80(8): 572.

14. Page P (2011) Shoulder Muscle Imbalance and Subacromial Impingement Syndrome in Overhead Athletes. Int J Sports Phys Ther 6(1): 5158.

15. Sommer HM (1988) Patellar Chondropathy and Apicitis, and Muscle Imbalances of the Lower Extremities in Competitive Sports. Sports Medicine 5(6): 386-394.

16. Schlumberger A, Laube W, Bruhn S, Herbeck B, Dahlinger M, et al (2006) Muscle imbalances - fact or fiction? Isokinetics and Exercise Science 14(1): 3-11.

17. Croisier JL, Ganteaume S, Binet J, Genty M, Ferret JM (2008) Strength Imbalances and Prevention of Hamstring Injury in Professional Soccer Players: A Prospective Study. The American Journal of Sports Medicine 36(8): 1469-1475.

This work is licensed under Creative

Commons Attribution 4.0 Licens

DOI: 10.19080/JPFMTS.2019.06.555695
18. Hébert Losier K, Rahman FA (2018) Reliability of postural measures in elite badminton players using Posture Pro 8. Physiotherapy Theory and Practice 34(6): 483-494.

19. Watson AW, Mac Donncha C (2000) A reliable technique for the assessment of posture: assessment criteria for aspects of posture. J Sports Med Phys Fitness 40(3): 260-270.

20. Padua DA, Hirth CJ (2007) Clinical Movement Analysis to Identify Muscle Imbalances and Guide Exercise. Athletic Therapy Today 12(4): 1014.

21. Oddsson LIE, De Luca CJ (2003) Activation imbalances in lumbar spine muscles in the presence of chronic low back pain. J Appl Physiol 94(4): 1410-1420.

22. Yung PSH, Chan RHK, Wong FCY, Cheuk PWL, Fong DTP (2007) Epidemiology of Injuries in Hong Kong Elite Badminton Athletes. Res Sports Med 15(2): 133-146.

23. Goh SL, Mokhtar AH, Mohamad Ali MR (2013). Badminton injuries in youth competitive players. J Sports Med Phys Fitness 53(1): 65-70.

24. Watson AW (2001) Sports injuries related to flexibility, posture, acceleration, clinical defects, and previous injury, in high-level players of body contact sports. International Journal of Sports Medicine 22(3): 222-225.

25. Watson AW (1995) Sports injuries in footballers related to defects of posture and body mechanics. J Sports Med Phys Fitness 35(4): 289294.

26. Wang H, Cochrane T (2001) Mobility impairment, muscle imbalance, muscle weakness, scapular asymmetry, and shoulder injury in elite volleyball athletes.

27. Devan MR, Pescatello LS, Faghri P, Anderson J (2004) A Prospective Study of Overuse Knee Injuries Among Female Athletes with Muscle Imbalances and Structural Abnormalities. Journal of Athletic Training, 39(3): 263-267.

28. Laffaye G, Phomsoupha M, Dor F (2015) Changes in the Game Characteristics of a Badminton Match: A Longitudinal Study through the Olympic Game Finals Analysis in Men's Singles. Journal of Sports Science \& Medicine 14(3): 584-590.

29. Phomsoupha M, Laffaye G (2015) The science of badminton: game characteristics, anthropometry, physiology, visual fitness and biomechanics. Sports Medicine (Auckland, NZ) 45(4): 473-495.

30. Manan V, Digpal R, Apoorva T, Manit A (2018) Analysis of static, dynamic, and pelvic stability in junior badminton players of South Asia. Journal of Sports Medicine and Therapy 3(4): 080-088.

31. Heitkamp HC, Horstmann T, Mayer F, Weller J, Dickhuth HH (2001) Gain in Strength and Muscular Balance After Balance Training. International Journal of Sports Medicine 22(4): 285-290.

Your next submission with Juniper Publishers
will reach you the below assets
- Quality Editorial service
- Swift Peer Review
- Reprints availability
- E-prints Service
- Manuscript Podcast for convenient understanding
- Global attainment for your research
- Manuscript accessibility in different formats
( Pdf, E-pub, Full Text, Audio)
- Unceasing customer service
Track the below URL for one-step submission
https://juniperpublishers.com/online-submission.php

